\title{
COVID-19 y Medicina centrada en la persona ¿es posible este binomio?
}

\author{
COVID-19 and Person-Centered Medicine, is this binomial possible?
}

\section{Señor Editor:}

Como médicos internistas hemos tenido la oportunidad de atender muchos pacientes con la COVID-19 durante esta pandemia. Esta situación ha puesto de manifiesto los problemas de nuestro sistema de salud ${ }^{(1)}$. Un punto álgido es la brecha en los recursos humanos calificados.

La presentación clínica es característica y dada la carencia de suficientes recursos humanos con especialidad y experticia en el manejo de estas personas, la brecha ha sido cubierta por médicos generales. Su participación, valiosa como loable, tiene sin embargo, algunos matices que preciso señalar.

Por un lado, asistimos a una carga asistencial agobiante. Ello, sin lugar a dudas trae consigo que el establecimiento de una adecuada relación médicopaciente/familiar cuidador sea deficiente. El miedo al contagio y la premura las decisiones clínicas calan en ello.

Por otro lado, se producen dos déficits claros: 1) Problemas en el enfoque de medicina centrada en la persona (MCP), que implica reduccionismo científico y deshumanización de la práctica médica ${ }^{(2)}$; y 2) de experticia en el abordaje del paciente en esta pandemia.

El que estemos en esta situación, no nos debe hacer olvidar que los pacientes crónicos: diabéticos, hipertensos, con problemas renales o con otras enfermedades, mantienen latente su carga de enfermedad, y que además de ser factores de mal pronóstico para la COVID-19, per se, pueden presentarse en nuestras emergencias. En nuestra opinión, estamos ante una "covidización" de la
Medicina, en la cual, todo paciente con síntomas respiratorios tiene COVID 19. La ventaja de esta estrategia, es el incremento de la sensibilidad, pero se pierde la especificidad, necesaria para que un sistema de salud sea eficiente, pero, produce déficits en la calidad de atención.

Citamos tres ejemplos que ilustran este problema.

Caso 1: mujer de 54 años, raza morena, diabética de larga data. Acudió al hospital con un tiempo de enfermedad de 10 días caracterizado por síntomas respiratorios y trastorno del nivel de conciencia. Al examen clínico PA: 120/80, FC: 100 x', FR: 24 x', afebril y saturación oxígeno de $99 \%$ con máscara de reservorio a $15 \mathrm{l} / \mathrm{min}$. Al examen preferencial se encontró: Mucosas secas; llenado capilar menor de 2 segundos, no había tiraje ni aleteo nasal; en estado de estupor, con movilización de las cuatro extremidades, no había signos de focalización ni rigidez de nuca. Fue catalogada como paciente con la COVID 19, y manejada con oxigenoterapia, ceftriaxona, enoxaparina y pulsos de $20 \mathrm{mg}$. En la evolución, en el análisis de gases arteriales (AGA) se halló $\mathrm{pH}: 7,1, \mathrm{HCO}_{3}: 8 \mathrm{mEq} / \mathrm{l}$, anion gap: 17, Na: 145 y K: 3,5. No hubo dosaje de cuerpos cetónicos. Además, urea y creatinina séricas elevadas. Fue manejada como cetoacidosis diabética y sin embargo, recibió algunas dosis de bicarbonato de sodio. Desarrolló hipernatremia $179 \mathrm{mEq} / 1$ que a pesar de la corrección con solución al medio normal y agua libre por SNG, no disminuyó. Falleció al quinto día.

Caso 2: mujer de 72 años, con antecedente de cirrosis de causa no filiada y várices esofágicas grado III, con episodio previo de endoligadura en el 2019. Tuvo contacto con caso positivo y asintomático de la COVID 19. La paciente tuvo una prueba rápida

\footnotetext{
Investigador Renacyt, Universidad Señor de Sipán.

Médico Internista Hospital Santa Rosa, Piura, Perú

Médico Gastroenterólogo, Clínica Auna Servimédicos Chiclayo.
} 
negativa. Cuatro días antes del ingreso presentó, melena y varios episodios de hematemesis de aproximadamente $1000 \mathrm{cc}$. Fue derivada a otro nosocomio y se le halla sin compromiso hemodinámico y $\mathrm{Hb} 9,0 \mathrm{~g} / \mathrm{dl}$. El médico gastroenterólogo planteó video endoscopía para realizar endoligadura. Por antecedente de contacto, se le tomó una tomografía torácica en la que se encontró signos sugerentes de la COVID 19. La paciente en ningún momento requirió oxígeno, transfusión de hemoderivados, y para la recepción de octreotide endovenoso, permaneció tres días en una unidad COVID.

Caso 3: mujer de 58 años, hipertensa, obesa y con antecedente de hipotiroidismo. Fue llevada a emergencia por presentar tos y dificultad respiratoria. En la nota de emergencia se registró saturación de oxígeno mayor de $95 \%$ con máscara de reservorio y se mencionó que "tiene tendencia al sueño". Recibió el manejo habitual para la COVID-19 y fue llevada a la Unidad Covid. Se le halló PA: 190/110, somnolienta, con déficit motor en hemicuerpo derecho e incoherente. La TAC cerebral mostró imagen de hemorragia subaracnoidea Fisher II en cisura de Silvio derecha, no signos de vaso espasmo y no hemorragias intraparenquimales. La TAC de tórax fue normal, sin alteraciones.

Estos ejemplos son probablemente, una realidad que está ocurriendo en los hospitales no sólo de nuestro país sino en otros. La cantidad de pacientes, la premura del tiempo y problemas con la experticia y la ausencia de una MCP, en la que el examen físico es uno de los pilares ${ }^{(3)}$, son potenciales causas que explican esta realidad.

Las características esenciales de la $\mathrm{MCP}$, son: a) compromiso ético; b) Marco holístico; c) sensibilidad y respuesta cultural; d) foco comunicativo y relacional; e) individualización del programa de atención clínica; f) establecimiento de una base común entre clínicos, paciente y familia para el entendimiento y la acción; g) organización de servicios integrados y centrados en las personas y la comunidad, y h) educación médica e investigación científica en salud centradas en la persona ${ }^{(4)}$, con lo cual queda claro, que no solo es una necesidad en este momento sino siempre, pues implica un compromiso ético que va más allá de una buena práctica médica en esta pandemia.
Sugerimos la implementación de capacitaciones estandarizadas y frecuentes con metodologías sencillas en el abordaje y manejo de las patologías que son entidades crónicas y que también actúan como factores de mal pronóstico en los pacientes con la COVID.

Conocer lo básico en ectosocopía del paciente respiratorio y neurológico, oxigenoterapia, electrocardiograma e interpretaciones del estado metabólico es una tarea pendiente de los que están organizando las brigadas de personal de salud.

Es el deber de quienes atendemos a estas personas, capacitar, inducir y estimular a los nuevos profesionales de la salud que están enfrentando esta pandemia para que su trabajo sea eficiente, medible y de calidad.

\section{Franco León-Jiménez ${ }^{1,2}$, Fernando Cubas-Benavides ${ }^{3}$}

\section{REFERENCIAS BIBLIOGRÁFICAS:}

1. Delgado D. La COVID-19 en el Perú: una pequeña tecnocracia enfrentándose a las consecuencias de la desigualdad. (Citado el 05 de julio del 2020). Disponible en: https://www.fundacioncarolina.es/ wp-content/uploads/2020/05/ac-26.-2020.pdf.

2. Perales A. Medicina centrada en la persona: del concepto a la acción. Revista Peru Med Exp Salud Publica. 2016; 33(4): 605-6.

3. Mezzich JE, Appleyard J, Botbol M, Ghebrehiwet T, Groves J, Salloum I, et al. International Journey and the Development of Person Centered Medicine (Editorial Introduction). Int J Pers Cent Med. 2014; 4(4):211-16

4. Mezzich JE. Repensando el Centro de la Medicina: de la enfermedad a la persona. Acta méd Per. 2010; 27(2):148-150.

5. Simons J, Vaughan J. Sacrifice and risk in the time of COVID-19. Future Health J. 2020 Jun; 7(2):158160. doi: 10.7861/fhj.2020-0035.

Recibido: $27 / 07 / 2020$

Aceptado: 05/12/2020 